\title{
SUBSTITUTION OF PRIMARY CARE AND SPECIALIST CARE: A REGIONAL ANALYSIS IN DENMARK
}

\author{
Peter P. Groenewegen \\ Netherlands Institute of Primary Health Care, NIVEL, P.O. Box 1568, 3500 BN Utrecht, The Netherlands
}

\begin{abstract}
A debate is going on in health care systems with capitation payment for general practitioner services about the disincentives of the system, leading to a low level of interventions by GPs and a high level of referrals. Increasing the fee-for-service element in the remuneration of GPs is seen as the remedy.

A mixed system of fee for service and capitation exists in Denmark. The fee for service part generates administrative data on the number of services. These data have been analysed at province level to find out whether or not a greater number of services by GPs in a province coincides with a lower level of hospital and specialist care. It proves that in provinces with a greater number of services by GPs the number of ambulatory hospital visits is smaller.
\end{abstract}

Key words-remuneration of general practitioners, substitution, regional analysis, Denmark

\section{INTRODUCTION}

The system of remuneration of health care professionals can be seen as a policy instrument for directing the behavior of health care professionals $[1,2]$. The goal of health policy in many Western European countries is to direct patient flows away from specialist and in-patient care to out-patient care and primary care [3]. The way in which general practitioners and medical specialists are being remunerated might influence the flow of patients.

A debate is going on in health care systems with capitation payment for general practitioner services (like the Netherlands) about the disincentives of the system, presumably leading to a low level of interventions by GPs and a high level of referrals [4]. Under capitation payment GPs receive a fixed amount of money per patient on their list, irrespective of the number of services rendered by the GP. According to Glaser [1] capitation payment might favor preventive care and continuity of care, but at the same time the risk exists of under-provision of more time-consuming and/or complicated curative services. GPs have no direct incentives to treat their patients themselves. Referral of patients has no consequences for their income, but does have for their amount of free time. Increasing the fee-for-service element in the remuneration of GPs is seen as the remedy.

The effects of different kinds of remuneration systems on the behavior of physicians have puzzled health services researchers for a long time. Changes in payment systems are ideally suited for research into their effects. However, usually these changes concern the system as a whole and are a part of broader system reforms, which makes it difficult to sort out different effects. Small-sized, experimental changes usually also imply elements of selection of physicians or patients. The same problems arise when different systems of payment exist alongside each other in health care systems. Moreover, the payment system of physicians is closely related to the broader institutional structure of health care (e.g. the way in which patients are being reimbursed). This makes it all the more difficult to attribute effects to the payment system. Finally, the behavioral mechanisms that connect the payment system and its presumed effects are not fully understood. Predictions based on the economic behavior of physicians are constrained by the role of ethical considerations.

In a situation like this, one can only try to find evidence for the effects of remuneration systems by studying the problem from a variety of different angles. In doing so small pieces of the puzzle can be added.

An interesting location for studying general practitioners' remuneration is the Danish health system, in which a mixed system of fee for service and capitation exists. In this paper I shall address one small piece of the puzzle, the question whether or not a mixed system of payment of GPs is conducive to substitution of primary care for specialist care.

The fee-for-service part of the remuneration of Danish GPs generates administrative data on the number of services. I have analysed these data at province level to find out whether or not a larger number of services by GPs in a province coincides with a lower level of hospital and specialist care. The behavioral model of GPs in this study is a very simple one: GPs are supposed to behave as income maximizers and therefore to react to separate payments for consultations and services by rendering more of them. In doing so some of these consultations and services are substitutes for specialists' consultations and services, and some groups of services are more likely to be substitutes for specialists' consultations and services (e.g. curative services by GPs) than other groups of services (e.g. diagnostic services by GPs).

The results of this analysis are particularly relevant to policy makers in health care systems in which capitation payment exists for GPs services. Of course, the results cannot be transferred directly to other systems of health care. First of all, there are other factors influencing the flow of patients, such as the availability and financing of hospital care and the 
method of payment of specialists [5]. Secondly, the data used in this analysis were not specially collected for the aim of this analysis, are used at a high level of aggregation and hence have their flaws. However, the analysis provides an opportunity to highlight one small part of the puzzling question of the effects of payment systems.

\section{DATA AND METHODS}

The data I shall use are not on the level of services rendered by individual GPs and the number of patients that these GPs refer or the number of patients admitted to hospitals. The data are on the aggregated level of the 'Amt' or province. The number of cases is therefore very small, 13 in total [6]. This is all the more reason to regard this analysis as a preliminary one.

The province is, however, a relevant unit of analysis. In the Danish health care system GPs' services and hospital planning are mainly administered at this level [7]. Patients cross provincial boundaries only to a minor degree [8].

For each province data were collected from administrative and statistical sources. As independent variables the number of services rendered by GPs is used. This is restricted to those services that are separately paid for. These services can be divided into basic services (consultations with GPs) and what are called additional services (separate items of diagnostic and therapeutic services) [9]. As dependent variables the number of ambulatory visits to the hospital and the number of hospital admissions are used [10].

We expect to find a negative relation between the amount of services rendered by GPs in a province and the number of ambulatory hospital visits and the hospital admission rate: the more services are being rendered by GPs, the lower will be the number of ambulatory visits and the hospital admission rate.

I shall look not only at the total number of services, but also at the frequency of particular groups of services. A relevant way of grouping services is to distinguish between diagnostic services and therapeutic services. Therapeutic services, rendered by the GPs themselves, might be seen as substitutes for specialist care. Diagnostic services performed by the GP, however, might also reveal morbidity that cannot be treated by the GPs themselves and hence may be a reason for referral after all. In this case it is expected that the correlation between the frequency of therapeutic services and the number of ambulatory visits and the hospital admission rate is stronger than the correlation between the frequency of diagnostic services and the dependent variables.

Of the therapeutic services a subgroup will also be looked at separately, namely the minor surgical procedures such as incision of abcesses, removal of warts and so on.

Of course there are other factors that also influence the flow of patients to specialist and hospital care. These factors should ideally be taken into account when evaluating the relation between the volume of GPs' services and the volume of ambulatory visits and hospital admissions [11]. On the demand side indicators for the health status of the population and the propensity to seek medical care in a province can be used. Indicators of the health status of the population are the age composition of the population and standardized mortality rates; urbanization and income level are indicators for the propensity to seek medical care [12]. On the supply side relevant indicators are the number of hospital beds, the size of hospitals, the availability of alternative beds in nurs. ing hospitals and the density of GPs and of independently practising specialists [13]. Data on these 'intervening' variables have also been collected for each province.

All data have been collected for 1982 .

As far as the method of analysis is concerned, the small number of provinces is the greatest problem. Ideally, a system of equations should be estimated [14], allowing for bidirectional causation between variables and weighting for the differences in size of the units of analysis. Practically, however, we can do no more than compute the correlations between the independent variables and the dependent variables, partializing one by one for the other variables known to influence the dependent variables.

Although correlation coefficients are known to be higher when computed at higher levels of aggregation, the small number of units of analysis might easily prevent the usual level of statistical significance from being reached. In the light of the exploratory character of the analysis, this is no great problem.

\section{RESULTS}

The zero-order correlations (see Table 1) show that the expected relations between GPs' services and hospital admissions are not found. Although four out of five separate correlations are negative, none of them reaches significance at the conventional 0.05 probability level.

The correlations of the number of GPs' services and the number of ambulatory hospital visits are much stronger. With the exception of the correlation with the number of GPs' contacts per 1000 patients, all correlations are significant.

The correlation is higher for the therapeutic services and the subgroup of minor surgical procedures than for the diagnostic services. The correlation

Table 1. Zero-order correlations between volume of GPs' services and volume of hospital services $(N=\lfloor 3)$

\begin{tabular}{lcc}
\hline GP services per & Hospital admissions & $\begin{array}{c}\text { Ambulatory visits } \\
\text { per } 1000 \text { inhabitants }\end{array}$ \\
\hline All contacts & per 1000 inhabitants & $-0.43(P=0.07)$ \\
All services & $-0.05(P=0.44)$ & $-0.67(P=0.00)$ \\
Diagnostic services & $-0.11(P=0.36)$ & $-0.56(P=0.02)$ \\
Therapeutic services & $0.05(P=0.44)$ & $-0.74(P=0.00)$ \\
Minor surgery services & $-0.40(P=0.09)$ & $-0.73(P=0.00)$ \\
\hline
\end{tabular}


Table 2. Correlations between volume of GPs' services and volume of hospital services, partializing for 'intervening' variables $(n=13)$ Partializing for:

\begin{tabular}{|c|c|c|c|c|c|c|c|c|c|c|}
\hline \multirow[b]{2}{*}{ Correlation between: } & \\
\hline & Zero-order & & $\begin{array}{l}\text { Inhabitants } \\
\text { per GP }\end{array}$ & $\begin{array}{c}\text { Inhabitants } \\
\text { per } \\
\text { specialist }\end{array}$ & & & & & & \\
\hline $\begin{array}{l}\text { Contact-admissions } \\
\text { All services-admissions } \\
\text { Diagnostic-admissions } \\
\text { Therapeutic-admissions } \\
\text { Surgery-admissions }\end{array}$ & $\begin{array}{c}-0.05 \\
-0.11 \\
0.05 \\
-0.40^{*} \\
-0.32\end{array}$ & $\begin{array}{l}-0.06 \\
-0.23 \\
-0.18 \\
-0.32 \\
-0.35\end{array}$ & $\begin{array}{l}-0.33 \\
-0.54^{* *} \\
-0.26 \\
-0.85^{* * *} \\
-0.62^{* *}\end{array}$ & $\begin{array}{r}0.03 \\
0.00 \\
0.20 \\
-0.38 \\
-0.28\end{array}$ & $\begin{array}{l}-0.19 \\
-0.31 \\
-0.09 \\
-0.64^{* *} \\
-0.51^{* *}\end{array}$ & $\begin{array}{l}-0.06 \\
-0.15 \\
0.00 \\
-0.43^{*} \\
-0.43^{*}\end{array}$ & $\begin{array}{l}3^{*} \\
5^{*} \\
0 \\
0^{* *} \\
4^{*}\end{array}$ & $\begin{array}{l}-0.31 \\
-0.42^{*} \\
-0.27 \\
-0.57^{* *} \\
-0.49^{*}\end{array}$ & $\begin{array}{l}4 \\
9 \\
9 \\
4 * * \\
3 *\end{array}$ & $\begin{array}{r}-0.05 \\
-0.11 \\
0.05 \\
-0.41^{*} \\
-0.32\end{array}$ \\
\hline $\begin{array}{l}\text { Contacts-ambulatory } \\
\text { All services-ambulatory } \\
\text { Diagnostic-ambulatory } \\
\text { Therapeutic-ambulatory } \\
\text { Surgery-ambulatory }\end{array}$ & $\begin{array}{l}-0.43^{*} \\
-0.67^{* * *} \\
-0.56^{* *} \\
-0.74^{* * *} \\
-0.73^{* * *}\end{array}$ & $\begin{array}{l}-0.43^{*} \\
-0.70^{* * *} \\
-0.65^{* *} \\
-0.73^{* * *} \\
-0.73^{* * *}\end{array}$ & $\begin{array}{l}-0.24 \\
-0.62^{* *} \\
-0.44^{*} \\
-0.70^{* * *} \\
-0.66^{* * *}\end{array}$ & $\begin{array}{l}-0.15 \\
-0.39 \\
-0.23 \\
-0.58 * \\
-0.51 *\end{array}$ & $\begin{array}{l}-0.25 \\
-0.55^{* *} \\
-0.42^{*} \\
-0.65^{* *} \\
-0.64^{* *}\end{array}$ & $\begin{array}{l}-0.43^{*} \\
-0.64^{* *} \\
-0.51^{* *} \\
-0.75^{* * *} \\
-0.67^{* *}\end{array}$ & $\begin{array}{l}-0.43^{*} \\
-0.70^{* * *} \\
-0.60^{* *} \\
-0.73^{* *} \\
-0.72^{* * *}\end{array}$ & $\begin{array}{l}-0.35 \\
-0.65^{* *} \\
-0.54^{* *} \\
-0.72^{* * *} \\
-0.70^{* * *}\end{array}$ & $\begin{array}{l}-0.28 \\
-0.56^{* *} \\
-0.40^{*} \\
-0.67^{* * *} \\
-0.67^{* * *}\end{array}$ & $\begin{array}{l}-0.47^{*} \\
-0.70^{* * *} \\
-0.59^{* *} \\
-0.78^{* * *} \\
-0.73^{* * *}\end{array}$ \\
\hline
\end{tabular}

$P<0.10$

$* * P<0.05$.

$* * P<0.01$

for the total number of services, the sum of the numbers of therapeutic and diagnostic services, is intermediate.

Hence, looking at the zero-order correlations only, the conclusion would be that the greater the number of services, especially the number of therapeutic services, rendered by GPs in a province, the smaller the number of ambulatory hospital visits in that province.

The results of the computation of partial correlations do not alter this picture greatly (see Table 2). First of all, only five out of ninety partial correlations are not negative. Secondly, the relations between the number of GPs' services and the number of hospital admissions and ambulatory visits are influenced by the density of GPs and of independently practising specialists on the supply side and by the percentage of elderly and average income on the demand side. Partializing for GP density, the strength of the correlations with admissions increases. The complete matrix of correlations (see Appendix) shows that a lower density of GPs coincides with fewer services per 1000 patients. Figure 1 shows the relationship between the number of therapeutic services of GPs and the number of hospital admissions in a scattergram; provinces with a high density of GPs have been marked in this figure. Particularly in provinces with a high density of GPs there is a strong correlation between the number of therapeutic services by GPs and the number of admissions [15]. Partializing for the density of independently practising specialists, the correlations between the number of GPs' services and the number of ambulatory visits decrease, but they are still significant for the number of therapeutic services and minor surgical procedures. A higher density of independently practising specialists coincides with more hospital admissions and ambulatory hospital visits and with a smaller number of services by GPs. Figure 2 shows the scattergram of the number of diagnostic services by GPs and the number of ambulatory hospital visits. The correlation between these two variables is strongly reduced when the density of independently practising specialists is controlled for. The high-density provinces have been marked in this figure. It seems as if independently practising specialists are not substituting for (ambulatory) hospital services, but increasing them.
Partializing for the percentage of elderly people and for the average income of the population shows more or less the same result: the correlation of the number of GPs' services and the number of hospital admissions is increased. The correlation matrix in the Appendix shows that a higher percentage of elderly coincides with more admissions and ambulatory visits and more services, especially diagnostic, of GPs. Lower-income provinces display more services by GPs and a higher percentage of elderly. The relation between the total number of services by GPs and the hospital admission rate is given in Fig. 3. In this figure the provinces with a low percentage of elderly have been marked. While the overall correlation is influenced by the outlying positions of province 3 on the one hand and province 8 on the other, these two provinces have a different percentage of elderly. This at least partly explains the higher correlation when the percentage of elderly is controlled for.
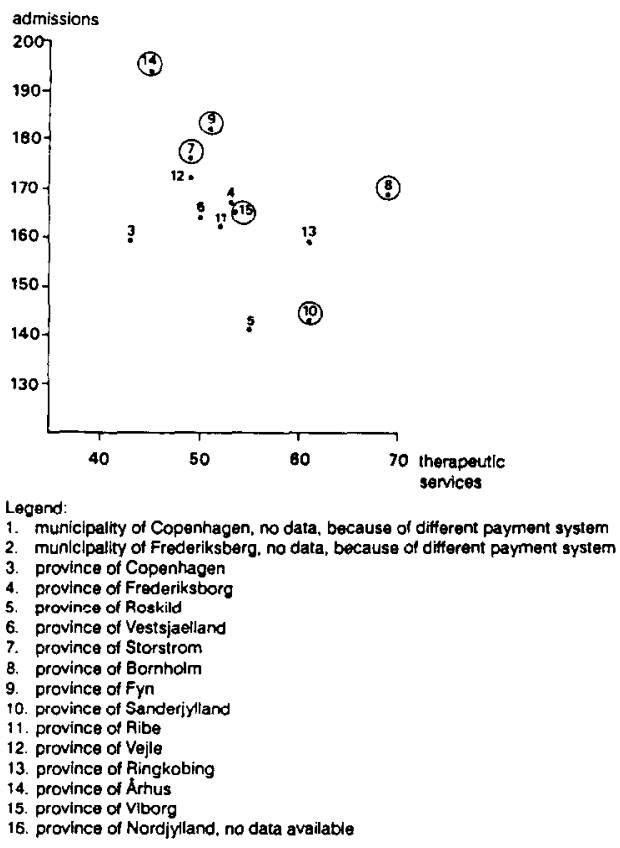

Fig. 1. Scattergram of the number of therapeutic services by GPs and hospital admissions per 1000 patients (provinces with a high density of GPs have been marked). 


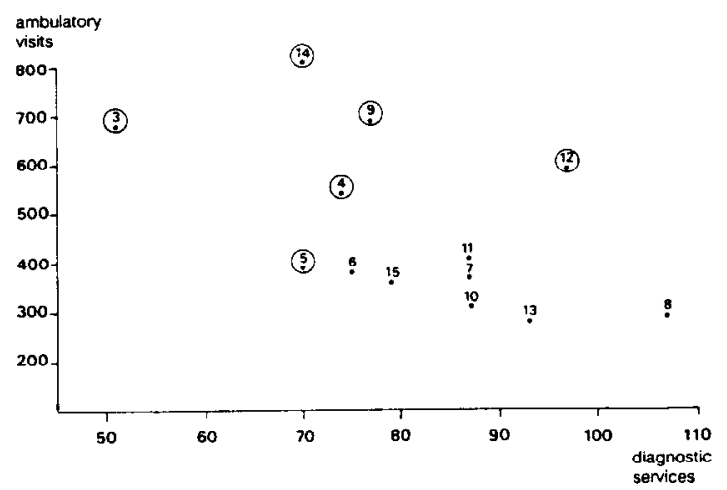

Fig. 2. Scattergram of the number of diagnostic services by GPs and ambulatory hospital visits per 1000 patients (provinces with a high density of independently practising specialists have been marked).

\section{DISCUSSION}

The background to this paper is the debate on the effects of professional remuneration systems on patients' flows. In policy discussions it is assumed that payment for separate services of GPs, as opposed to capitation payment, induces GPs to render more services to their patients, and that an increased level of services by GPs leads to lower levels of utilization of hospital and specialist care. Research to underscore these assumptions is relatively scarce.

The Danish health care system proved to be a case in which this research is possible from different angles. The fact that until the fall of 1987 a system of capitation payment existed in the municipalities of Copenhagen and Frederiksberg, made it possible to compare levels of GPs' services under capitation and under a mixed system of capitation and fee for service (in the wider province of Copenhagen) [16]. This comparison showed that GPs under capitation payment rendered fewer services to their patients than under the mixed system.

The opportunity of a change in Copenhagen City from capitation payment to a mixed system of capitation and fee for service was taken to investigate the effects of a change in payment [17]. It turned out

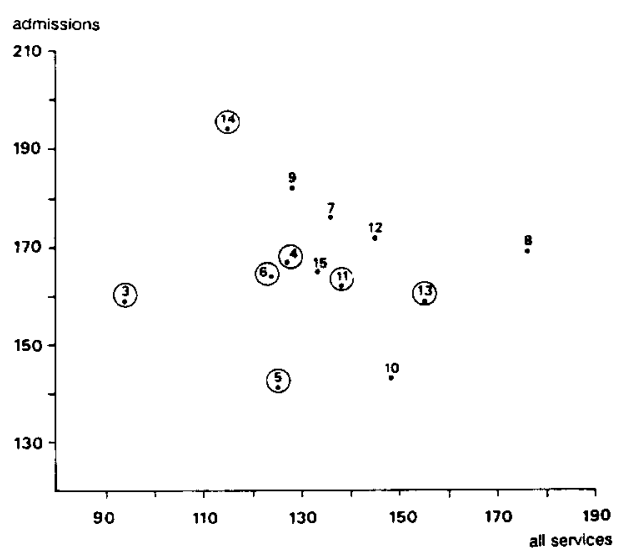

Fig. 3. Scattergram of the total number of services by GPs and hospital admissions per 1000 patients (provinces with a low percentage of elderly people have been marked). that the change in payment led to a greater increase in the number of services of GPs than in a control group of GPs and to a decrease of the number of referrals.

The effects of changes in other parts of the institutional structure, in this case the system of reimbursement of patients, could be studied when a conflict arose between the GPs' organizations and the provincial authorities. Normally, all services of GPs are in kind in Denmark. When this system was suspended during a conflict over tariffs, patients had to pay directly to the GPs and were totally reimbursed later. As an effect of this, the flow of patients towards the outpatient emergency departments of hospitals increased [18].

In this paper I have looked at the effects of remuneration systems from yet another angle: the differences between provinces with a higher level of GPs' services and those with a lower level of these services in a situation in which all GPs are partly paid on a fee-for-service basis. It emerges that in provinces with a greater number of services by GPs, in particular the number of ambulatory hospital visits is smaller.

The level of aggregation of the data used is very high and, although the data on GPs' services are available at the level of specific services, the flow of patients to hospital and specialist care is very crudely indicated. From the results presented in this paper it seems to me that it is fruitful to analyse data on the Danish health system at lower levels of aggregation. These data do exist in principle, and it will be further explored how and under what conditions they can be used. In further research, special attention should be paid to the role of independently practising specialists in the Danish health system and to the consequences of differences in the density of GPs for the relations between the volume of GP services and the volume of hospital services.

\section{REFERENCES}

1. Glaser W. A. Paying the Doctor: Systems of Remunera tion and their Effects. Johns Hopkins University Press, Baltimore, 1970.

2. Rosen B. Professional reimbursement and professional behavior; emerging issues and research challenges. Soc. Sci. Med. 29, 455, 1989.

3. Kirkman-Liff B. L. and van de Ven W. P. M. M. Improving efficiency in the Dutch health care system: current innovations and future options. Health Policy 13, 35, 1989.

4. Ham C., Robinson R. and Benzeval M. Health Check: Health Care Reforms in an International Context. King's Fund Institute, London, 1990.

5. Glaser, W. A. Paying the Hospital: The Organization, Dynamics and Effects of Differing Financial Arrangements. Jossey-Bass, San Francisco, 1987.

6. There are:14 provinces and 2 municipalities with the same status. In the municipalities of Copenhagen and Frediriksberg, a different payment system existed at the time these data were collected (capitation). Data on GPs services for one province (Nordjylland) were not available.

7. Descriptions of the Danish health care system can be found in Raffel M. W. (Ed.) Comparative Health Systems: Descriptive Analysis of Fourteen National Health Systems. Pennsylvania State University Press, Univer- 
sity Park, PA, 1984; Krasnik A. et al. Den Primaere Sundhedsjeneste i Danmark. Sundhedstyrelsen, Copenhagen, 1982.

8. The percentage of hospital admissions of people living in the province where they were admitted varies from $88 \%$ (in the province of Arhus) to $98 \%$ (in the province of Sonderjylland).

9. An overview of these services at the country level is regularly published in the Sygesikringsstatistik, Sygesikringens Forhandlingsudvalg, Copenhagen.

10. Data on hospital admissions and ambulatory visits were taken from: Forbruget af Somatiske Sengepladser, Sundhedsstyrelsen, Copenhagen, 1982.

11. Van der Zee $J$. and Groenewegen P. P. General and specific factors in the explanation of regional variation in hospital admission rates: policy consequences for Belgium and the Netherlands. Hilh Policy 8, 77, 1987.

12. Data on demand-side variables were taken from: Statistiksårbog, 1983; Danmarks Statistik, Indkomster og formner, 1982, and Sundhedsstyrelsen, Dodsårsagerne, 1982.

13. Data on supply-side variables were taken from: Sundhedsstyrelsen, Personale og Okonomistatistik for Sygehusvaesenet, 1982, Aktiviteten i Sygehusvaesenet, 1982, Praksisoplysninger, 1982, and Statistiksårbog, 1983.
14. Compare, for example, Rutten F. F. H. and van der Gaag J. Referrals and the demand for specialist care in the Netherlands. Hlth Services Res. 12, 233, 1977.

15. Province 8 , the isle of Bornholm, is something of an exception. This small island with only 47,000 inhabitants in 1982 , has an average admission rate but a high volume of GP services and the highest density of GPs of all provinces. Province 14, Arhus, has a very high admission rate; this is also the province with the highest percentage of admissions of people living in another province.

16. Flierman H. A. and Groenewegen P. P. Capitation fee and fee for service: a comparative study of Danish general practice. 1lth Int. Con. Social Sciences and Medicine, Noordwijkerhout, The Netherlands, 1989.

17. Krasnik A. et al. Changing remuneration systems: effects on activity in general practice. Br. Med. J. 300, 1698, 1990.

18. Hansen B. W. L. Effekten af en afgift pa laegeydelser vurderet ved antallet af vagthenvendelser. Ugeskrift for Laeger 148, 247, 1986; Krogsgaard M. R. et al. Skadestuebelastning og indlaeggelses-monster under PLO-konflikten i efteratet 1984. Ugeskrift for Laeger 147, 4025, 1985; Wolthers O. D. and Stellfeld M. Skadestuehenvendelser $i$ en periode med patientbetaling for laegeydelser i almen praksis. Ugeskrifi for Laeger 148, $975,1986$.

Appendix-see overleaf 


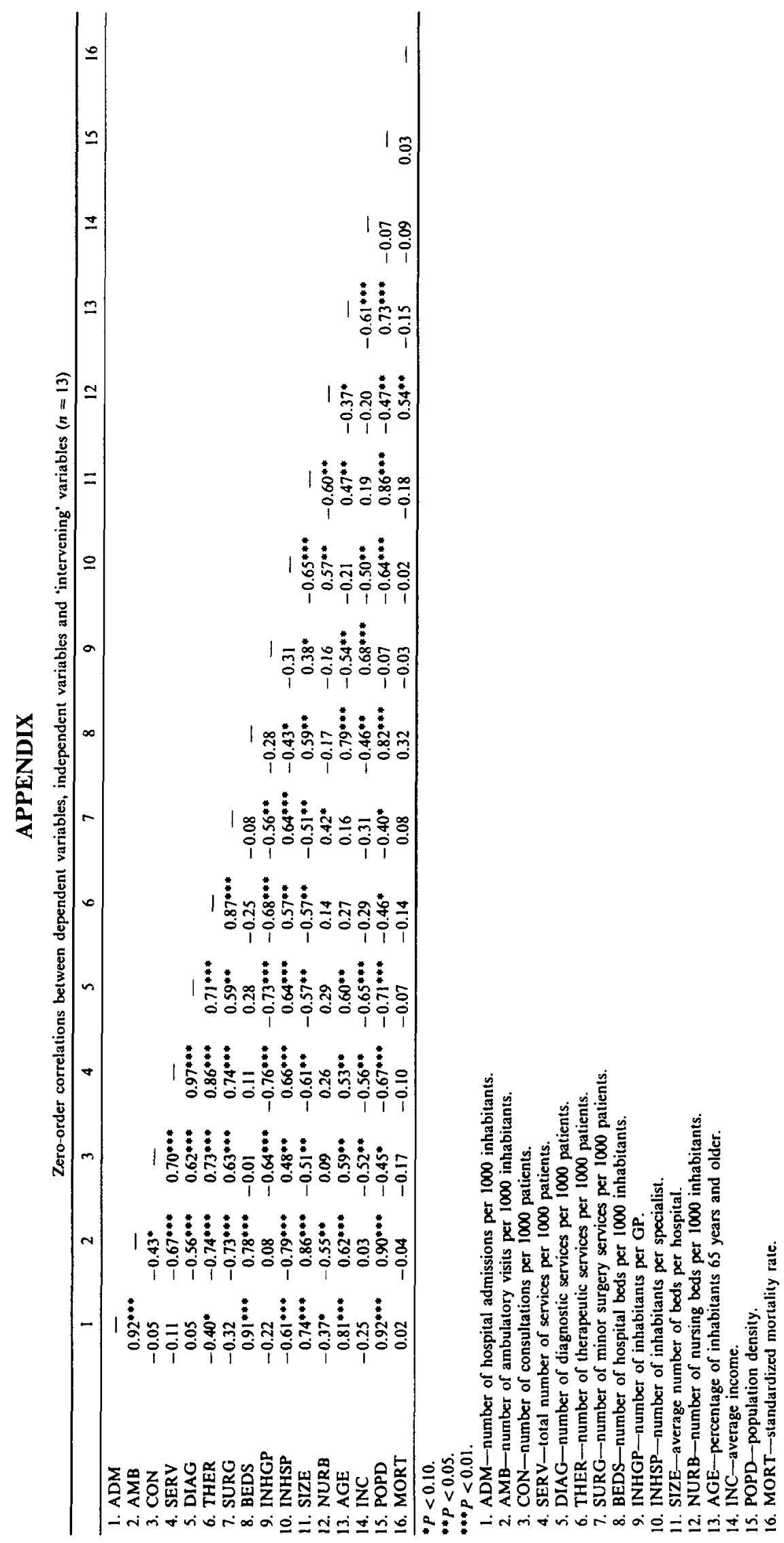

